\title{
Porous titanium granules in critical size defects of rabbit tibia with or without membranes
}

\author{
Rafael Arcesio Delgado-Ruiz ${ }^{1}$, Jose Luis Calvo-Guirado², Marcus Abboud ${ }^{1}$, Maria Piedad Ramirez-Fernández ${ }^{2}$, \\ Jose Eduardo Maté-Sánchez ${ }^{2}$, Bruno Negri ${ }^{2}$, Alex Won ${ }^{1}$ and Georgios Romanos ${ }^{1}$
}

Recently, porous titanium granules (PTGs) have been indicated for the preservation of the dimensions of post-extraction sockets, as a filler in sinus lift procedures and for the treatment of peri-implant and periodontal defects, based on the osteoconductivity and dimensional stability of the titanium granules. However, there is a lack of information regarding the use of this material in larger defects and in conjunction with membranes. The objective of this study is to test the behavior of PTGs used to fill critical size defects in rabbit tibiae, with and without membranes. Critical defects were created in both tibiae of rabbits, divided randomly into three groups: Group A (defect filled with PTG), Group B (defect filled with PTG+collagen membrane) and a control group (empty defect). After six weeks, histomorphometric analysis was performed. The results showed more defect closures at the cortical area $(87.37 \% \pm 2.2 \%)$ and more bone formation at the marrow area $(57.6 \% \pm 1.3 \%)$ in Group B, in comparison with the other groups $(P<0.05)$; the use of membranes improved the material stability expressed as more percentages of the original material when membranes were used $(P<0.05)$. Finally, inflammatory reactions were observed when the granules were not protected by membranes. In spite of the limitations of this animal study, it may be concluded that PTG particles are osteoconductive and allow bone growth. The PTG particles must be covered by a membrane, especially when grafting larger defects, in order to control particle migration, promote clot stabilization and separate the PTG graft from undesired soft tissue cells.

International Journal of Oral Science (2014) 6, 105-110; doi:10.1038/ijos.2014.6; published 21 February 2014

Keywords: bone substitutes; collagen membranes; critical size defects; histomorphometry; titanium granules

\section{INTRODUCTION}

Although autologous grafts are considered the gold standard for grafting materials due to their well-known osteoinductive and osteogenous properties, some degree of resorption must be expected. ${ }^{1-4}$ The augmented zones can undergo a conversion process, which can lead to a considerable decrease in bone over time after augmentation. ${ }^{2,5}$

Alternative allografts, xenografts and alloplastic graft materials have been widely employed clinically as substitutes or supplements to autologous bone to reduce the disadvantages of donor zone morbidity and the resorption rate of the autologous bone. ${ }^{6-9}$ Deproteinated bovine bone grafts and some ceramic grafts are more stable than autologous bone because of their slow resorption. ${ }^{10}$ In addition, these materials represent the most commonly used grafting material for bone regeneration in the orofacial zone. ${ }^{11-12}$

Recently, porous titanium granules (PTGs) have been indicated for the preservation of the dimensions of the post-extraction socket, ${ }^{13-15}$ as a filler in sinus lift procedures ${ }^{16-19}$ and for the treatment of periimplant $^{20-22}$ and periodontal defects. ${ }^{23-24}$

These granules have a diameter between $700 \mu \mathrm{m}$ and $1000 \mu \mathrm{m}$ with a pore size larger than $50 \mu \mathrm{m}$ in diameter. The granules are approximately $80 \%$ porous, and the total titanium surface of the granules is close to $2 \mathrm{~cm}^{25}$ The use of titanium granules has been tested in orthopedic surgery for the fixation of femoral stems, and the results have been very promising given the granules' osteoconductivity and high dimensional stability. Histology results from clinical and experimental studies have shown bone formation in and around the granules. ${ }^{26-28}$

Given the metallic-gray color of the PTG particles, their use is mainly recommended for the posterior zone, and their use in the esthetic zone is precluded, especially in thin biotypes, to overcome this limitation. New, oxidized white PTGs were tested in socket preservation; however, the obtained bone volume was lower $(50.3 \%)$ than that of empty controls $(57.1 \%)$ and conventional PTG $(61.7 \%)$ particles. $^{14}$

According to the manufacturer's recommendations, the material must not overfill the defect, primary closure is recommended and, in wide bony defects, the use of a membrane to ensure a sufficient blood supply should be considered. PTG belongs to a class of material that may be preferable for filling cavities because it serves as a nonresorbable scaffold that promotes a tridimensional matrix, which can stabilize and maintain the shape of the filled area.

However, there is a lack of information in the literature regarding the use of this material in larger defects and in conjunction with the use

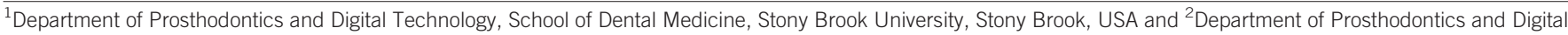
Technology, School of Medicine and Dentistry, Murcia University, Murcia, Spain

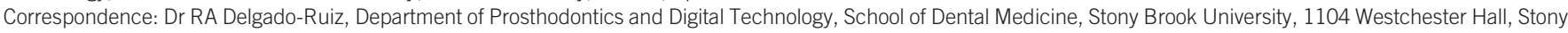
Brook NY 11794-7812, USA

E-mail: Rafael.Delgado-Ruiz@stonybrookmedicine.edu

Received 10 July 2013; Accepted 11 November 2013 
of membranes. For that reason, the purpose of the present study was to demonstrate the behavior of PTG in critical size defects in rabbit tibias (with and without membranes) using histological and histomorphometrical analysis.

\section{MATERIALS AND METHODS}

The study protocol was approved by the University of Murcia Animal Experimentation Ethics Committee (October 2011) in compliance with Royal Decree 1201, 10 October 2005, and Article 32 of November 7/ 2007 for the protection of animals used for experimental procedures.

\section{Experimental animals}

Twenty-one New Zealand adult male rabbits weighing $(3.51 \pm 0.2) \mathrm{kg}$ were used. The animals were kept in individual cages and were fed and watered ad libitum.

\section{Anesthesia and drug administration}

The specimens received an intramuscular injection of $0.5-1 \mathrm{mg} \cdot \mathrm{kg}^{-1}$ acepromazine maleate. Fifteen minutes later, general anesthesia included 5-8 $\mathrm{mg} \cdot \mathrm{kg}^{-1} \mathrm{ketamine}$ plus chlorbutol administered intravenously, with $0.05 \mathrm{mg} \cdot \mathrm{kg}^{-1}$ atropine as a co-adjuvant.

Both tibiae were shaved and washed with $1.5 \%$ aqueous chlorhexidine digluconate. The medial sections of both tibiae were exposed via a skin incision and careful subperiosteal dissection. One or two critical-size defects $6 \mathrm{~mm}$ in diameter ${ }^{29}$ were randomly performed in the proximal metaphyseal-diaphyseal area using trephine surgical drills at a low speed and constant irrigation using a previously described scheme. ${ }^{30}$ The randomization scheme was generated using the website http://www.randomization.com.

Sixty-three defects were created and distributed into the following groups: the test groups Group A (21 defects) and Group B (21 defects) and the control group (21 defects). One group of defects (Test A) was filled with $0.702 \mathrm{~cm}^{3}$ of PTG (Tigran PTG; Tigran Technologies AB, Malmö, Sweden) with a particle size between 0.7 and $1 \mathrm{~mm}$. The second group of defects (Test B) was filled with the same material and volume and covered with an Alveoprotect collagen membrane (Bredent Medical GmbH \& Co. KG, Senden, Germany). The third group of defects was left empty, and no membranes were used (Control; Figure 1).
Amoxicillin $\left(0.1 \mathrm{mg} \cdot \mathrm{kg}^{-1}\right.$ intramuscularly) was administered at the end of the surgery. The rabbits were euthanized via an intracardiac overdose of thiopental 6 weeks after the graft placement.

\section{Sample processing and optical microscopy}

Blocks containing the entire graft area were obtained using a precision saw. The obtained samples were fixed by immersion in $4 \%$ formalin solution, dehydrated in a graded ethanol series and embedded in plastic resin (Technovit A 7210 VCL; Kulzer \& Co., Hanau, Germany). Posteriorly, the samples were sectioned to $100-\mu \mathrm{m}$ thickness using a diamond saw (Exakt Apparatebau; Norderstedt, Hamburg, Germany) and ground and polished to a final thickness of 30-40 $\mu \mathrm{m}$ using an Exakt 400 CS grinding device (Exakt Apparatebau; Norderstedt, Hamburg, Germany).

Two central sections were obtained and stained using the Levai Laczko method and then examined with light microscopy (Leica microscope Q500 Mc; Leica Microsystems, Barcelona, Spain). Histomorphometry was performed in two regions of interest (ROIs): the cortical area $\left(\mathrm{ROI}_{1}\right)$ and the marrow area $\left(\mathrm{ROI}_{2}\right.$; Figure 2$)$.

The following histomorphometric measurements were recorded:

- cortical defect closure (CDC): the percentage of new bone present between the original defect walls in $\mathrm{ROI}_{1}$;

- new bone (NB): the percentage of new bone present inside the marrow space and between the PTG particles in $\mathrm{ROI}_{2}$;

- connective tissue (CT): the connective tissue or the connective tissue space present inside $\mathrm{ROI}_{1}$ and $\mathrm{ROI}_{2}$, expressed as a percentage;

- residual material (RM): The percentage of particles present inside $\mathrm{ROI}_{1}$ and $\mathrm{ROI}_{2}$ in relation to the total area of each zone.

Histomorphometric measurement of the samples was conducted using ImageJ software (ImageJ; US National Institutes of Health, Bethesda, MD, USA). A square grid of $100 \times 100$ test lines with square micro-areas of $300 \mu \mathrm{m}$ at $\times 5$ and $\times 10$ magnifications was used to determine and measure the previously mentioned variables. Three measurements were recorded, and the mean values for each variable were calculated.

\section{Statistical analysis}

Normality tests (Kolmogorov-Smirnov and Shapiro-Wilk) were applied without any observed violation assumptions. Variance of

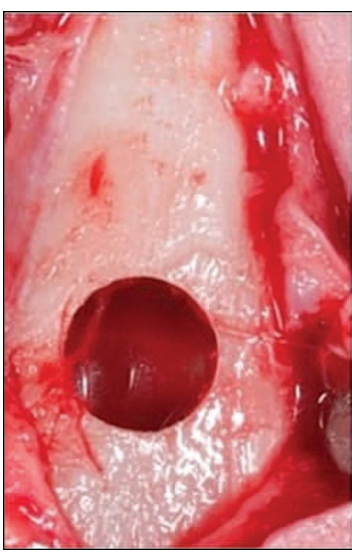

Control

No material

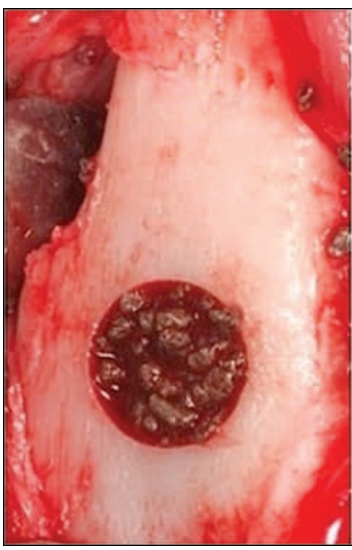

Group A PTG

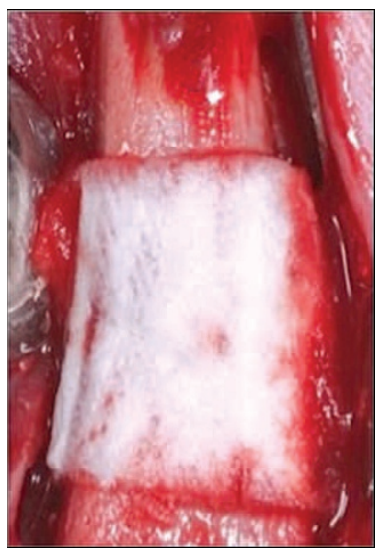

Group B

PTG+membrane

Figure 1 Critical size defect of $6 \mathrm{~mm}$ diameter. The images shown in the three groups used in the study: control at the left, Group A at the center and Group B at the right. PTG, porous titanium granule. 


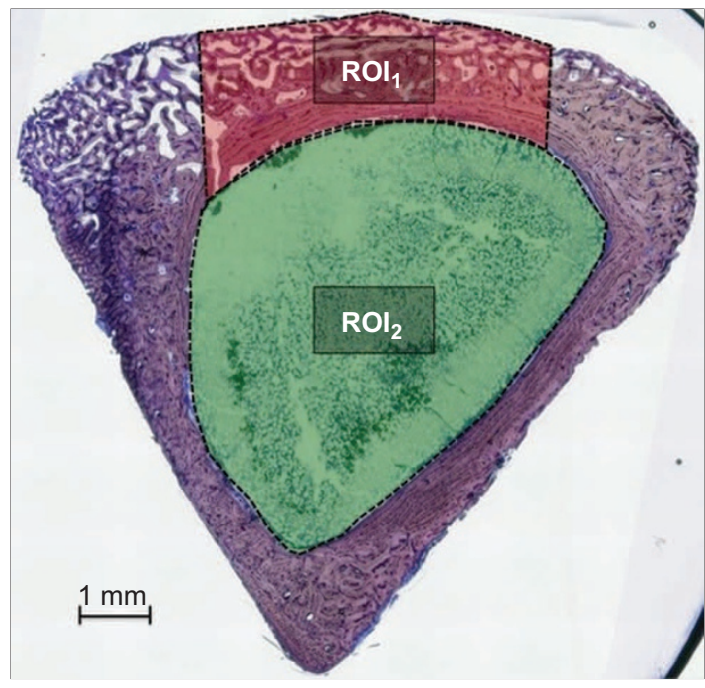

Figure 2 ROI areas. Processed image showing the regions of interest at the cortex in red $\left(\mathrm{ROI}_{1}\right)$ and at the marrow in green $\left(\mathrm{ROI}_{2}\right)$. The $\mathrm{CDC}, \mathrm{NB}, \mathrm{CT}$ and RM were measured for each region. Toluidine blue staining, magnification $\times 5$. $\mathrm{CDC}$, cortical defect closure; CT, connective tissue or its space; NB, new bone; $\mathrm{RM}$, residual material; ROI, region of interest.

analyses were performed posteriorly. To identify significant differences between groups, Bonferroni's post hoc analysis was used. Mean values and standard deviations between samples were calculated for each variable. The significance was set as $P<0.05$.

\section{RESULTS}

Cortical defect closure

All of the groups showed an approximation of the borders and a subsequent reduction of the original defect size. Group B, in which the PTG

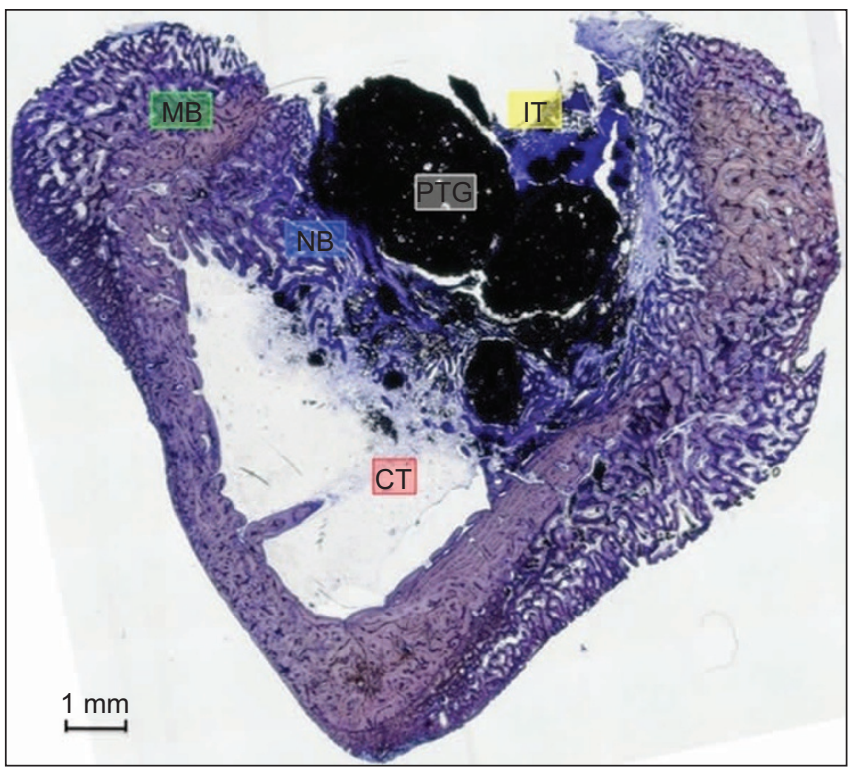

Figure 3 Group A. PTG particles were missing in some areas, partial cortical closure was present, bone formation was evident around the base of the particles and between them, and inflammatory tissue was detected at the coronal aspect of the particles. Toluidine blue staining, magnification $\times 5$. CT, connective tissue or its space; IT, inflammatory tissue; MB, mature bone; NB, new bone; PTG, porous titanium granule. material was inserted and covered by a membrane, showed almost complete defect closure $(87.37 \% \pm 2.2 \%)$, and a mixture of new bone and PTG particles formed the new cortical. No membrane residues were observed. Group A, in which the PTG material was inserted without a membrane, showed partial loss and displacement of the particles outside the defect and partial closure $(53.1 \% \pm 7.4 \%)$; inflammatory tissue around the particles on the outer area of the cortical bone was evident. The control group showed a partial defect closure $(57.6 \% \pm 4 \%)$ and a thinner cortical area $(P<0.05$; Figures 3-5 and Table 1$)$.

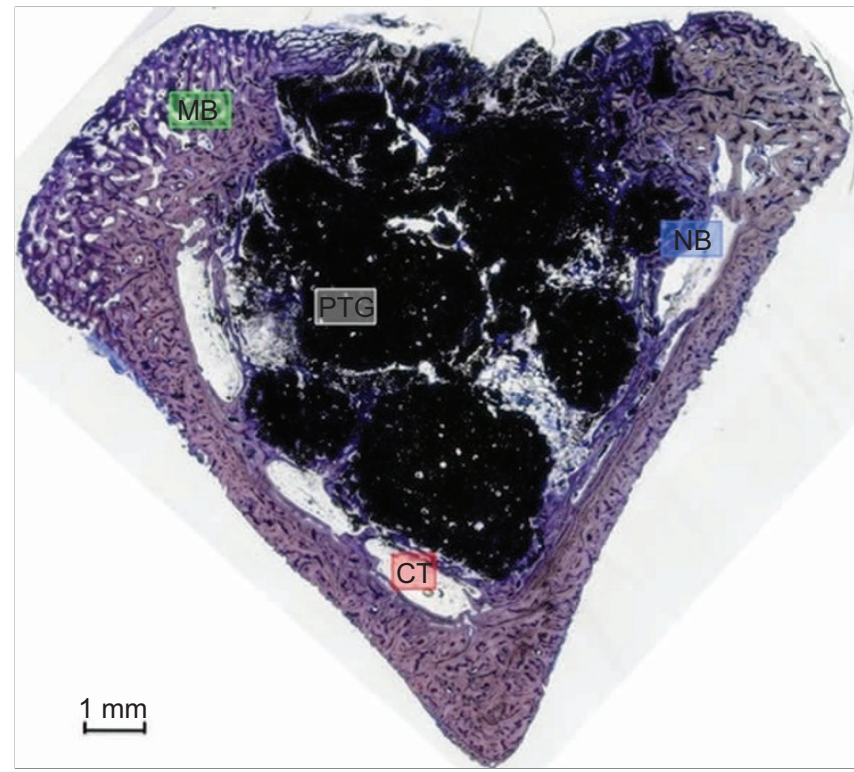

Figure 4 Group B. Almost a complete defect closure was observed. Bone formation was evident around particles, especially in particles that were in contact with cortical areas. The connective tissue or their space was minimal compared with Group A. A higher number of PTG particles were observed. Bone formation bridging the cortical bone and the particles was appreciated. Toluidine blue staining, magnification $\times 5$. CT, connective tissue or its space; $M B$, mature bone; NB, new bone; PTG, porous titanium granule.

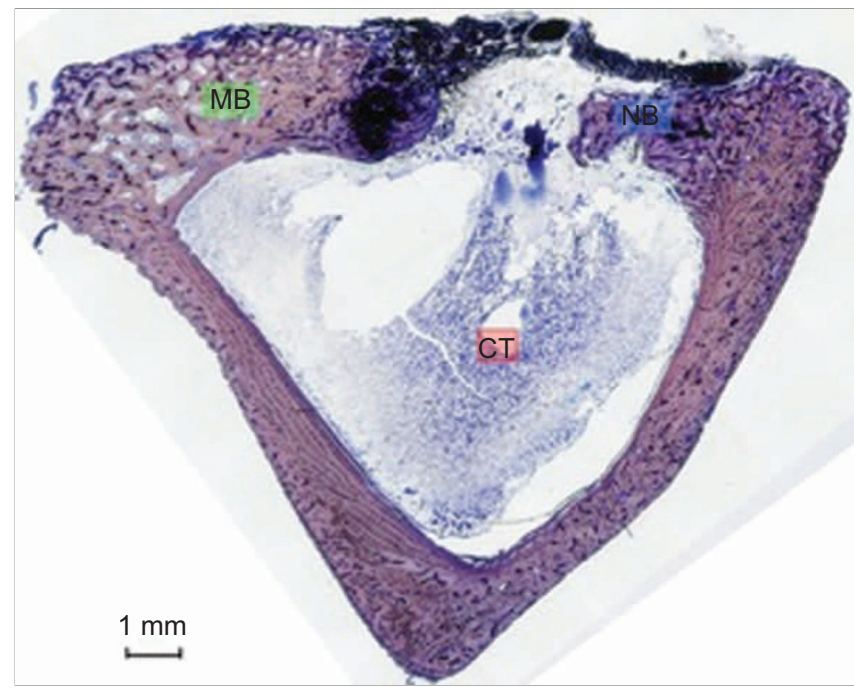

Figure 5 Control group. After 6 weeks, partial defect closure and new thin cortical bone were observed. The bone growth originated in the borders of the defect. The $\mathrm{ROI}_{2}$ area was completely filled by $\mathrm{CT}$, and no bone formation was appreciated inside the marrow space. Toluidine blue staining, magnification $\times 5$. CT, connective tissue or its space; $\mathrm{MB}$, mature bone; $\mathrm{NB}$, new bone; $\mathrm{ROI}$, region of interest. 
Table 1 Histomorphometry of $\mathrm{ROI}_{1}$

\begin{tabular}{lccc}
\hline & \multicolumn{3}{c}{ Histomorphometry data } \\
\cline { 2 - 4 } Tissue & Group A & Group B & Control \\
\hline Cortical defect closure & $53.1 \pm 7.4$ & $87.4 \pm 2.2^{*}$ & $57.6 \pm 4.0$ \\
Connective tissue & $33.6 \pm 2.0$ & $14.3 \pm 5.0$ & $47.0 \pm 4.5^{*}$ \\
Residual material & $16.3 \pm 8.0$ & $63.0 \pm 1.7 *$ & 0 \\
\hline
\end{tabular}

ROI, region of interest.

Mean \pm standard deviation values expressed as percentages by group. $* P<0.05$.

Group B showed the highest percentages of defect closure and higher amounts of residual material. The control group showed the highest connective tissue percentages.

\section{New bone}

NB grew between the PTG particles in Groups B and A; however, in the control group, the new bone was only present in the cortical $\mathrm{ROI}_{1}$ area and was absent in the $\mathrm{ROI}_{2}$ area. We commonly observed that the bone formation started in the particles that contacted the cortical bone and grew in a centripetal manner to the center of the $\mathrm{ROI}_{1}$ and $\mathrm{ROI}_{2}$ (Figures 6 and 7).

The highest amount of bone was found in Group B, followed by Group A and the control group in $\mathrm{ROI}_{2}$; however, the presence of $\mathrm{NB}$ was higher in the periphery than in the central areas of the PTG particle grafted area (Figure 8 and Tables 1 and 2).

\section{Connective tissue}

Among the three groups, the CT was the highest for the control group at $\mathrm{ROI}_{1}(47 \% \pm 4.5 \%)$ and $\mathrm{ROI}_{2}(95.8 \% \pm 3.2 \%)$ and the lowest for Group B in both ROI areas $(P<0.05$; Tables 1 and 2$)$.

\section{Residual material}

Group B showed a higher percentage of residual material in both regions compared with Group A $(P<0.05$; Tables 1 and 2).

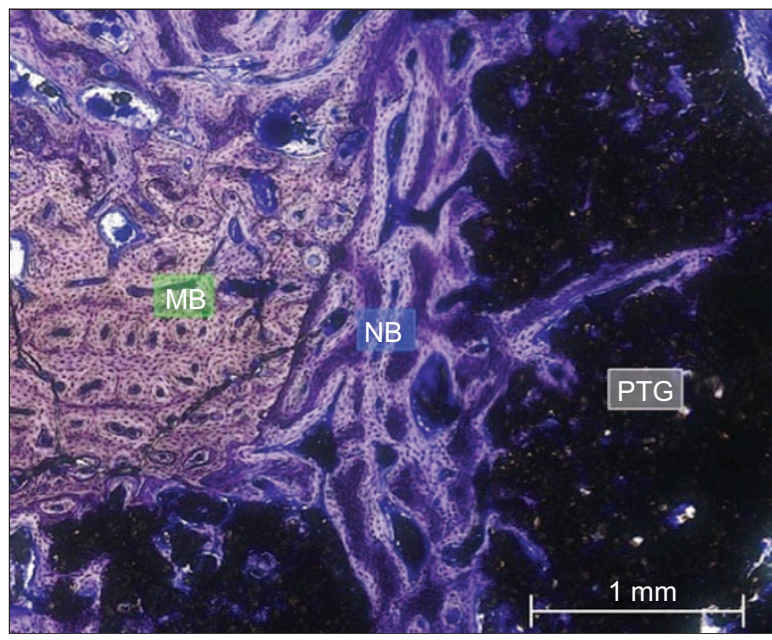

Figure 6 Close view Group B. The PTG granules were osteoconductive, as they supported bone formation; inside the granules, some bone was present. From the left to the right side, MB displays the characteristic lamellar organization. On the left, the NB formation started with a greater number of blood vessels; at the right, in the darker color, the PTGs are observed with bone formation between the particles and inside the pores, but almost none were detected in connective tissue. Toluidine blue staining, magnification $\times 5$. MB, mature bone; NB, new bone; PTG, porous titanium granule.

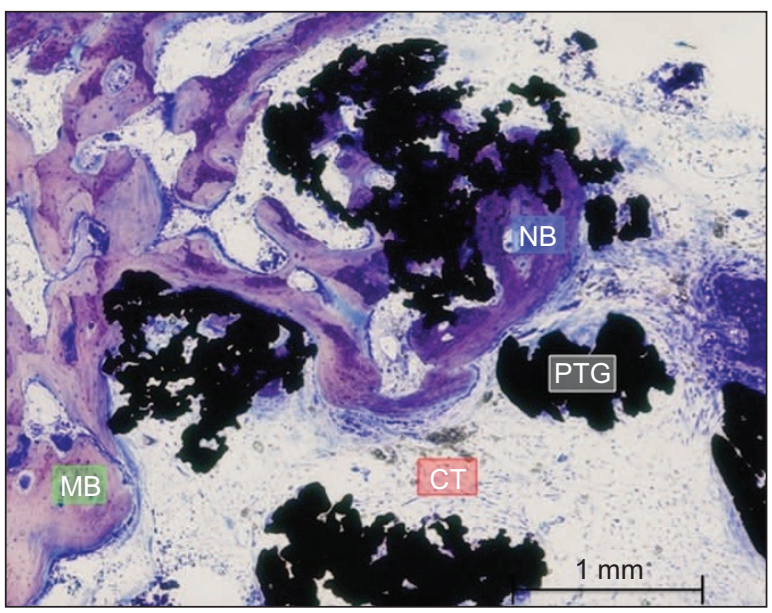

Figure 7 Close view Group A. Connective tissue was present between particles, with some bone formation around and inside some granules; however, other particles were surrounded only by connective tissue. The particles were mainly visible in the vicinity of the defect walls, not in the medullar area, most likely as result of particle movement and primary connective tissue formation. Toluidine blue staining, magnification $\times 15$. CT, connective tissue or its space; $\mathrm{MB}$, mature bone; NB, new bone; PTG, porous titanium granule.

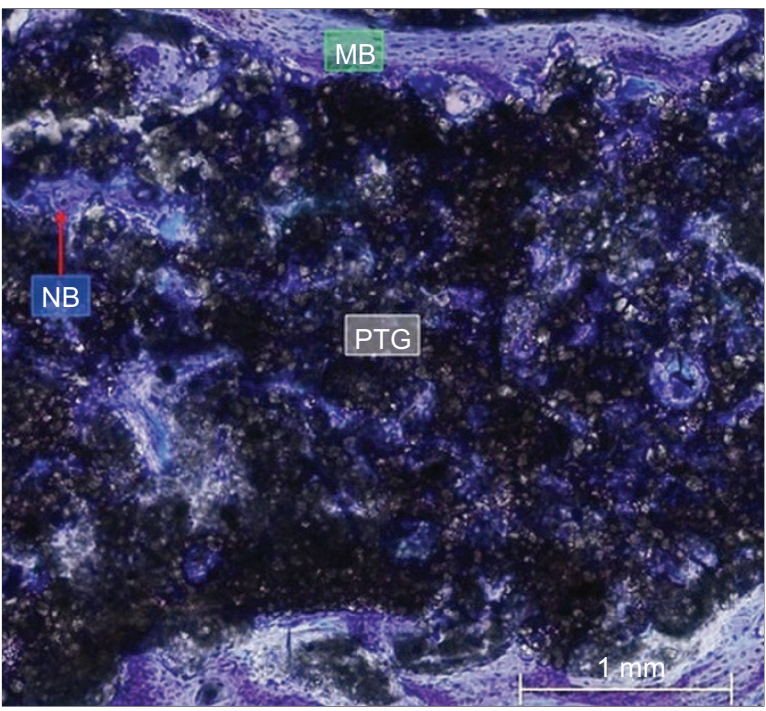

Figure 8 Close view of the central portion of the graft with membrane. Bone formation in the center and the periphery of the graft was evident. Especially in areas with greater porosity and areas with smaller pores, a bone matrix was appreciated. The red arrow shows new bone formation. Toluidine blue staining, magnification $\times 20$. MB, mature bone; NB, new bone; PTG, porous titanium granule.

Table 2 Histomorphometry of $\mathrm{ROI}_{2}$ $1 \%$

\begin{tabular}{lccc}
\hline & \multicolumn{3}{c}{ Histomorphometry data } \\
\cline { 2 - 4 } Tissue & Group A & Group B & Control \\
\hline New bone formation & $26.6 \pm 1.7$ & $57.6 \pm 1.3^{*}$ & $6.8 \pm 0.7$ \\
Connective tissue & $67.2 \pm 3.5$ & $29.0 \pm 2.0$ & $95.8 \pm 3.2^{*}$ \\
Residual material & $28.7 \pm 2.8$ & $67.0 \pm 3^{*}$ & 0 \\
\hline
\end{tabular}

ROI, region of interest.

Mean \pm standard deviation values expressed as percentages by group. $* P<0.05$.

Group B showed the highest NB percentages and higher amounts of RM. The Control group showed the highest connective tissue percentages. 


\section{DISCUSSION}

The purpose of the present work was to study the behavior of PTG in critical-sized defects in rabbit tibias with and without membranes to better evaluate the behavior of the material.

Regarding the CDC obtained in the present study, PTG granules used with membranes (Group B) showed the best cortical closure (close to $90 \%$ ). The material stabilized by the membrane provided support for the new bone formation and demonstrated excellent osteoconductivity.

This finding could be explained by the protective effects of the membrane, as described previously by Dahlin et al. ${ }^{31}$ and Buser et al. ${ }^{32}$ These protective effects consist of stabilization of the material, providing a barrier for the surrounding soft tissues and limiting resorption.

In the specific case of the PTG particles that did not undergo a resorptive process, they need the protection of the surrounding soft tissues to avoid fibrous encapsulation of the particles and avoid bacterial contamination if they are exposed to the oral media. ${ }^{33-34}$

Without the use of a membrane (Group A), many particles were mobilized outside the grafted site. In that way, the inflammatory response was initiated, and the complete closure of the defect was limited. However, even though the PTG particles are osteoconductive, ${ }^{17,26-28}$ it seems that immobilization is necessary to avoid the displacement of the material caused by the animal's movements, which can facilitate additional inflammatory reactions in the surrounding tissues. ${ }^{15}$

These results are in agreement with an exhaustive review of various augmentation procedures, ${ }^{35}$ which concluded that the use of membranes was essential for successful outcomes with bone grafting procedures.

In a previous model performed by Wohlfahrt et al. ${ }^{28}$ two different particles of PTG were inserted and covered by titanium coins with Teflon caps in 3-mm-diameter defects in rabbit tibia. Other defects were left as controls. After 4 weeks of healing, the researchers found that both PTG groups were osteoconductive; they concluded that PTG may be used safely adjacent to titanium.

There are differences between the defect size used by Wohlfahrt et al. which is not a critical defect, and the critical defect size used in the present investigation which have been described previously. ${ }^{29-30}$

Those findings are in agreement with the results of the present work, in which the PTG particles were osteoconductive. However, all of the defects received a protective cover, and the effect of the presence or absence of a membrane was not tested in this investigation. In addition, the size of the bone defect created by Wohlfahrt et al. was only $3 \mathrm{~mm}$, which does not represent a critical-sized defect in rabbits.

Furthermore, PTG granules were used in a pilot report with sinus grafting procedures in 11 patients, presenting another indication of the use of PTG in implant dentistry. ${ }^{19}$ However, it is not clear whether the material can be used successfully for two-stage sinus lift procedures because of the possible risk of displacement of the granules and insufficient stability of the implant during site preparation. Further studies should evaluate this application in animal models.

NB formation was allowed by the presence of graft particles inside both ROI areas. The NB was present surrounding the particles and between them and the cortical zone; however, the central area of the grafted zone did not feature NB.

An explanation could be the distance between the cortical areas and the central area, as was explained by Sivolella et al., ${ }^{36}$ who created defects of different sizes in dog jaws using a special device where dental implants were inserted and stabilized. The researchers found that the size of the defect affected the NB formation; the bigger the defect, the less NB formation was expected.
The osteoconductive properties of the PTG used in the present work were evident; however, their indications are still limited to posterior zones (molar or premolar areas). Recently, Thor $^{22}$ reported clinical cases in which PTGs were used in the canine and premolar areas around peri-implant defects. Their observations recommend the use of PTG in combination with membranes to improve the outcomes and reduce the loss of granules. This recommendation is in agreement with our results and recommendations regarding the use of membranes in conjunction with PTG granules.

A further disadvantage of PTG might be the behavior of a metallic material upon exposure to the oral environment, especially if it is used for lateral augmentations or in combination with implants. In cases of infections, nonmetal bone grafts (such as Bio-Oss) might be treated as described by Urban et al. ${ }^{37}$ with the use of a surgical and pharmacological regimen that salvages the graft and does not necessitate complete removal of the graft. This regimen was confirmed by the success of the treatment in all of the treated patients; however, its effectiveness for treating infected PTG grafts is unknown.

The sample size and the model used in the present work have limitations, given that the model did not resemble all of the clinical indications of this material. However, it was clear that the results were related to the particles loosening and the absence of a membrane. As a consequence of the results obtained at the present work and considering that more than $65 \%$ of the material was lost without the use of a membrane, we strongly recommend the use of membranes in conjunction with PTG particles for large defects.

\section{CONCLUSIONS}

Despite the limitations of this animal study, we can conclude that PTG particles are osteoconductive and may allow bone growth. The PTG particles must be covered by a membrane, especially when grafting larger defects, to control particle dislocation, promote clot stabilization and separate the PTG graft from undesired soft tissue cells.

1 Nkenke E, Radespiel-Troger M, Wiltfang J et al. Morbidity of harvesting of retromolar bone grafts: a prospective study. Clin Oral Implants Res 2002; 13(5): 514-521.

2 Wiltfang J, Schultze-Mosgau S, Nkenke E et al. Onlay augmentation versus sinus lift procedure in the treatment of the severely resorbed maxilla: a 5-year comparative longitudinal study. Int J Oral Maxillofac Surg 2005; 34(8): 885-889.

3 Brugnami F, Caiazzo A, Leone C. Local intraoral autologous bone harvesting for denta implant treatment: alternative sources and criteria of choice. Keio J Med2009; 58(1): 24-28.

4 Becker ST, Warnke PH, Behrens E et al. Morbidity after iliac crest bone graft harvesting over an anterior versus posterior approach. J Oral Maxillofac Surg 2011; 69(1): 48-53.

5 Binger T, Hell B. Resorption of microsurgically vascularized bone grafts after augmentation of the mandible. J Craniomaxillofac Surg 1999; 27(2): 82-85.

6 Tadjoedin E, de Lange GL, Bronckers AL et al. Deproteinized cancellous bovine bone (Bio-Oss) as bone substitute for sinus floor elevation. J Clin Periodontol 2003; 30(3): 261-270.

7 Cordaro L, Bosshardt DD, Palattella $\mathrm{P}$ et al. Maxillary sinus grafting with Bio-Oss or Straumann Bone Ceramic: histomorphometric results from a randomized controlled multicenter clinical trial. Clin Oral Implants Res 2008; 19(8): 796-803.

8 Galindo-Moreno P, Avila G, Fernández-Barbero JE et al. Clinical and histologic comparison of two different composite grafts for sinus augmentation: a pilot clinical trial. Clin Oral Implants Res 2008; 19(8): 755-759.

9 Lee CY, Rohrer MD, Prasad HS. Immediate loading of the grafted maxillary sinus using platelet rich plasma and autologous bone: a preliminary study with histologic and histomorphometric analysis. Implant Dent 2008; 17(1): 59-73.

10 Umanjec-Korac S, Wu G, Hassan B et al. A retrospective analysis of the resorption rate of deproteinized bovine bone as maxillary sinus graft material on cone beam computed tomography. Clin Oral Implant Res 2013; doi: 10.1111/clr.12174. [Epub ahead of print].

11 Cardaropoli G, Araújo M, Hayacibara R et al. Healing of extraction sockets and surgically produced-augmented and non-augmented-defects in the alveolar ridge. An experimental study in the dog. J Clin Periodontol 2005; 32(5): 435-440.

12 Araújo M, Linder $\mathrm{E}$, Wennström J et al. The influence of Bio-Oss collagen on healing of an extraction socket: an experimental study in the dog. Int J Periodontics Restorative Dent 2008; 28(2): 123-135. 
13 Bashara $\mathrm{H}$, Wohlfahrt JC, Polyzois I et al. The effect of permanent grafting materials on the preservation of the buccal bone plate after tooth extraction: an experimental study in the dog. Clin Oral Implants Res 2012; 23(8): 911-917.

14 Verket A, Lyngstadaas SP, Rønold HJ et al. Osseointegration of dental implants in extraction sockets preserved with porous titanium granules-an experimental study. Clin Oral Implants Res 2013; 25(2): e100-e108.

15 Tavakoli M, Moghareabed A, Farsam T et al. Evaluation of dental socket healing after using of porous titanium granules: histologic and histomorphometric assessment in dogs. Dent Res J 2012; 9(5): 600-606.

16 Lambert $F$, Lecloux $G$, Léonard $A$ et al. Bone regeneration using porous titanium particles versus bovine hydroxyapatite: a sinus lift study in rabbits. Clin Implant Dent Relat Res 2013; 15(3): 412-426.

17 Bystedt $\mathrm{H}$, Rasmusson L. Porous titanium granules used as osteoconductive material for sinus floor augmentation: a clinical pilot study. Clin Implant Dent Relat Res 2009; 11(2): 101-105.

18 Verket A, Lyngstadaas SP, Rasmusson L et al. Maxillary sinus augmentation with porous titanium granules: a microcomputed tomography and histologic evaluation of human biopsy specimens. Int J Oral Maxillofac Implants 2013; 28(3): 721-728.

19 Vandeweghe S, Leconte C, Ono D et al. Comparison of histological and threedimensional characteristics of porous titanium granules and deproteinized bovine particulate grafts used for sinus floor augmentation in humans: a pilot study. Implant Dent 2013; 22(4): 339-343.

20 Wohlfahrt JC, Lyngstadaas SP, Rønold HJ et al. Porous titanium granules in the surgical treatment of peri-implant osseous defects: a randomized clinical trial. Int $J$ Oral Maxillofac Implants 2012; 27(2): 401-410.

21 Mijiritsky E, Yatzkaier G, Mazor Z et al. The use of porous titanium granules for treatment of peri-implantitis lesions: preliminary clinical and radiographic results in humans. Br Dent J 2013; 214(5): 1-3.

22 Thor A. Porous titanium granules and blood for bone regeneration around dental implants: report of four cases and review of the literature. Case Rep Dent 2013; 2013: 410515.

23 Wohlfahrt JC, Lyngstadaas SP, Heijl L et al. Porous titanium granules in the treatment of mandibular Class II furcation defects: a consecutive case series. J Periodontol 2012; 83(1): 61-69.

24 Wohlfahrt JC, Aass AM, Rønold HJ et al. Microcomputed tomographic and histologic analysis of animal experimental degree II furcation defects treated with porous titanium granules or deproteinized bovine bone. J Periodonto/ 2012; 83(2): 211-221.

25 Carbone M, Goss E, Borione M et al. Implant supported prostheses with bone system implant system: a restrospective study with follow-up period up to 13 years about 1,021 fixtures. Minerva Stomatol 2007; 56(10): 481-495.

26 Alffram PA, Bruce L, Bjursten LM et al. Implantation of the femoral stem into a bed of titanium granules using vibration. Upsala J Med Sci 2007; 112(2): 183-189.
27 Turner TM, Urban RM, Hall DJ et al. Bone ingrowth through porous titanium granulate around a femoral stem. Histologic assessment in a six-month canine hemiarthoplasty model. Upsala J Med Sci 2007; 112(2): 191-197.

28 Wohlfahrt JC, Monjo M, Ronold HJ et al. Porous titanium granules promote bone healing and growth in rabbit tibia periimplant osseous defects. Clin Oral Implants Res 2010; 21(2): 165-173.

29 Le Guehennec L, Goyenvalle E, Aguado E et al. Small-animal models for testing macroporous ceramic bone substitutes. J Biomed Mater Res B Appl Biomater 2005; 72(1): 69-78.

30 Calvo-Guirado JL, Delgado-Ruíz RA, Ramírez-Fernández MP et al. Histomorphometric and mineral degradation study of Ossceram: a novel biphasic B-tricalcium phosphate in critical size defects in rabbits. Clin Oral Implants Res 2012; 23(6): 667-675.

31 Dahlin C, Linde A, Gottlow J et al. Healing of bone defects by guided tissue regeneration. Plast Reconstr Surg 1988; 81(5): 672-676.

32 Buser D, Dula K, Hess D et al. Localized ridge augmentation with autografts and barrier membranes. Periodontol 2000 1999; 19(1): 151-163.

33 Becker W, Becker BE, Caffesse R. A comparison of demineralized freeze-dried bone and autologous bone to induce bone formation in human extraction sockets. J Periodontol 1994; 65(2): 1128-1133.

34 Becker W, Clokie C, Sennerby L et al. Histologic findings after implantation and evaluation of different grafting materials and titanium micro screws into extraction sockets: case reports. J Periodontol 1998; 69(4): 414-421.

35 Esposito M, Grusovin MG, Coulthard $P$ et al. The efficacy of various bone augmentation procedures for dental implants: a Cochrane systematic review of randomized controlled clinical trials. Int J Oral Maxillofac Implants 2006; 21(5): 696-710.

36 Sivolella S, Bressan E, Salata LA et al. Osteogenesis at implants without primary bone contact — an experimental study in dogs. Clin Oral Implants Res 2012; 23(5): 542_ 549.

37 Urban IA, Nagursky H, Church $\mathrm{C}$ et al. Incidence, diagnosis, and treatment of sinus graft infection after sinus floor elevation: a clinical study. Int J Oral Maxillofac Implants 2012; 27(2): 449-457

(c) (i) (\$) $\Theta$ This work is licensed under a Creative Commons Attribution-

(c) 1 BY NC ND NonCommercial-NoDerivs 3.0 Unported License. The images or other third party material in this article are included in the article's Creative Commons license, unless indicated otherwise in the credit line; if the material is not included under the Creative Commons license, users will need to obtain permission from the license holder to reproduce the material. To view a copy of this license, visit http://creativecommons.org/licenses/ by-nc-nd/3.0/ 